Article

\title{
Evaluation of Carbohydrates in Natural and Cultured Cordyceps by Pressurized Liquid Extraction and Gas Chromatography Coupled with Mass Spectrometry
}

\author{
Jia Guan ${ }^{1}$, Feng-Qing Yang ${ }^{1,2}$ and Shao-Ping $\mathrm{Li}^{1}{ }^{1, *}$ \\ 1 Institute of Chinese Medical Sciences, University of Macau, Macao, China \\ 2 Department of Pharmaceutics, College of Chemistry and Chemical Engineering, Chongqing \\ University, Chongqing, China
}

* Author to whom correspondence should be addressed; E-Mail: lishaoping@hotmail.com; Tel.: +853-8397 4692; Fax: +853-2884 1358.

Received: 31 May 2010; in revised form: 9 June 2010 / Accepted: 10 June 2010 /

Published: 11 June 2010

\begin{abstract}
Free and polymeric carbohydrates in Cordyceps, a valued edible mushroom and well-known traditional Chinese medicine, were determined using stepwise pressurized liquid extraction (PLE) extraction and GC-MS. Based on the optimized PLE conditions, acid hydrolysis and derivatization, ten monosaccharides, namely rhamnose, ribose, arabinose, xylose, mannose, glucose, galactose, mannitol, fructose and sorbose in 13 samples of natural and cultured Cordyceps were qualitatively and quantitatively analyzed and compared with myo-inositol hexaacetate as internal standard. The results showed that natural C. sinensis contained more than $7.99 \%$ free mannitol and a small amount of glucose, while its polysaccharides were usually composed of mannose, glucose and galactose with a molar ratio of 1.00:16.61 3.82:1.60 1.28. However, mannitol in cultured C. sinensis and cultured C. militaris were less than $5.83 \%$, and free glucose was only detected in a few samples, while their polysaccharides were mainly composed of mannose, glucose and galactose with molar ratios of 1.00:3.01 1.09:3.30 1.05 and 1.00:2.86 1.28:1.07 0.78, respectively. Natural and cultured Cordyceps could be discriminated by hierarchical clustering analysis based on its free carbohydrate contents.
\end{abstract}


Keywords: Cordyceps; carbohydrates; polysaccharides; pressurized liquid extraction (PLE); GC-MS

\section{Introduction}

Carbohydrates, including free and polymeric saccharides (polysaccharides), are usually considered the principal substrates of energy metabolism [1]. They also play important roles in nutrition and therapeutics [2,3]. In fact, fungi-derived polysaccharides have attracted a great deal of attention because of their significant pharmacological activities [4,5].

Cordyceps, a famous and valued medicinal material, is commonly used as a health food and Traditional Chinese Medicine for replenishing the kidneys and soothing the lungs in the treatment of various diseases [6,7]. It contains high amounts of carbohydrates, which can range from 3 to $8 \%$ of the total dry weight [8]. Most biological properties of Cordyceps can be attributed the presence of polysaccharides [9-15] which are regarded as potential markers for its quality control [8]. To date, though the sugars [16,17] and polysaccharides [18] in Cordyceps have been determined, complete profiles and contents of free and polymeric carbohydrates in natural and cultured Cordyceps are still not available.

Gas chromatography (GC) has been used as a powerful qualitative and quantitative tool for carbohydrate analysis [19-21]. Non-volatile carbohydrates can be converted to volatile derivatives, such as trimethylsilyl ether and acetate derivatives [22], amenable to GC analysis. In particular aldononitrile acetate derivatization is widely used due to its short sample preparation time, stable derivatized products and single chromatographic peak for each neutral saccharide [23], as well as its high reliability in qualitative and quantitative analysis [24-28]. The current study describes a method for the qualitative and quantitative determination of free carbohydrates and polysaccharides in natural and cultured Cordyceps using pressurized liquid extraction (PLE) and GC-MS. Their saccharide content characteristics were also compared.

\section{Results and Discussion}

\subsection{Optimization of Derivatization}

This operation involved two steps: oximation and acylation [28]. A previous study had shown that completed derivatization was markedly influenced by the amount of hydroxylamine hydrochloride used, the temperature and duration of oximation, as well as temperature and duration of acylation [29], hence these factors were investigated to obtain stable and maximum total response ratios of saccharides to internal standard (IS).

Due to fact that the presence of impurities could increase under high reaction temperatures, the temperature was optimized under $100{ }^{\circ} \mathrm{C}$. The results showed the optimum derivatization conditions involve mixing the analytes with a suitable ratio $(\mathrm{mg} / \mathrm{mg} \geq 1)$ of hydroxylamine hydrochloride and reacting at $90{ }^{\circ} \mathrm{C}$ for $30 \mathrm{~min}$, then acetic anhydride (50 $\mu \mathrm{L}$ per $1 \mathrm{mg}$ of each analyte) is added to the cooled solution and the reaction continued at $90{ }^{\circ} \mathrm{C}$ for $30 \mathrm{~min}$ (Figure 1). 
Figure 1. Optimization of derivatization of 10 investigated saccharides.

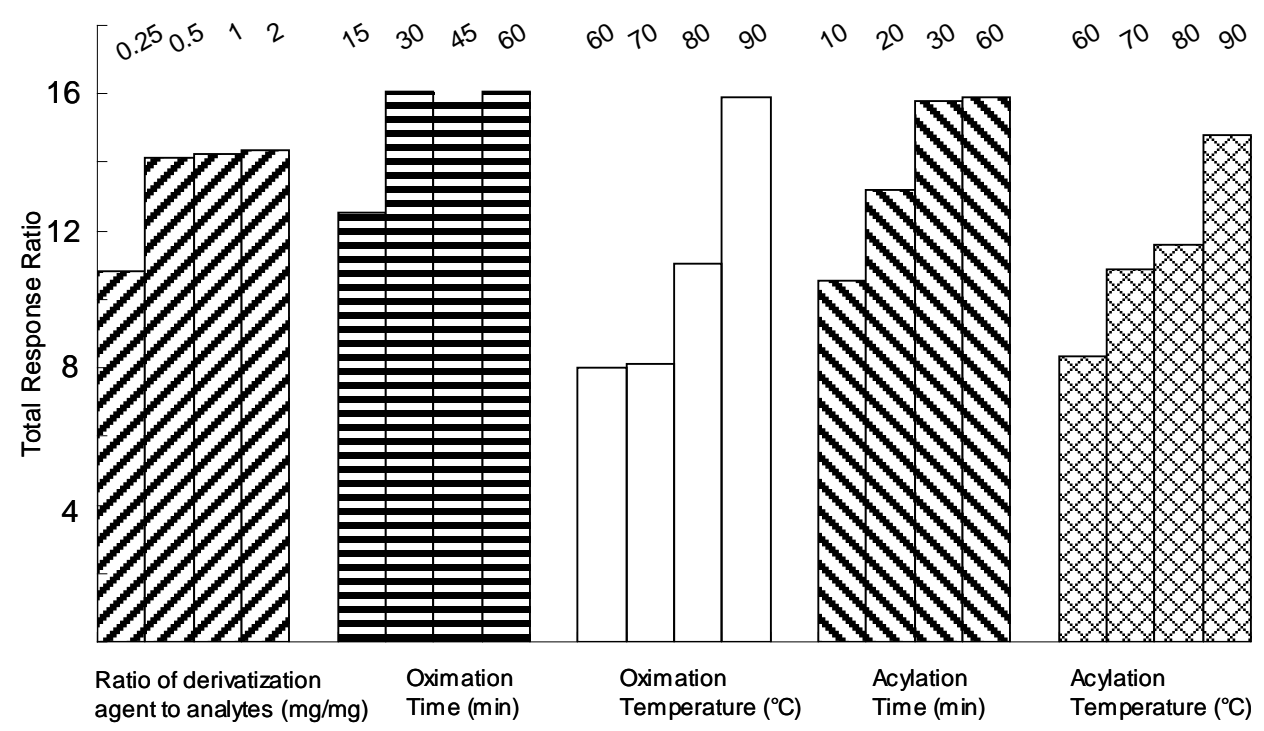

\subsection{Optimization of Trifluoroacetic Acid (TFA) Hydrolysis}

TFA hydrolysis is a commonly used for hydrolysis of polysaccharides from Cordyceps [13,15]. To ensure complete release of compositional saccharides from the polysaccharides, a stable and maximum total response ratio of detected carbohydrates to IS was used as marker for evaluation of the hydrolysis efficiency. Figure 2 shows the effects of concentration of TFA, hydrolysis time and hydrolysis temperature on the total response ratio of the investigated saccharides. High concentration of TFA could induce the destruction of released saccharides and less hydrolysis time could result in incomplete hydrolysis. Finally, the optimized hydrolysis conditions were: concentration of TFA, $2 \mathrm{~mol} \cdot \mathrm{L}^{-1}$; temperature, $100{ }^{\circ} \mathrm{C}$; hydrolysis time, $2 \mathrm{~h}$.

Figure 2. Optimization of TFA hydrolysis of polysaccharides.

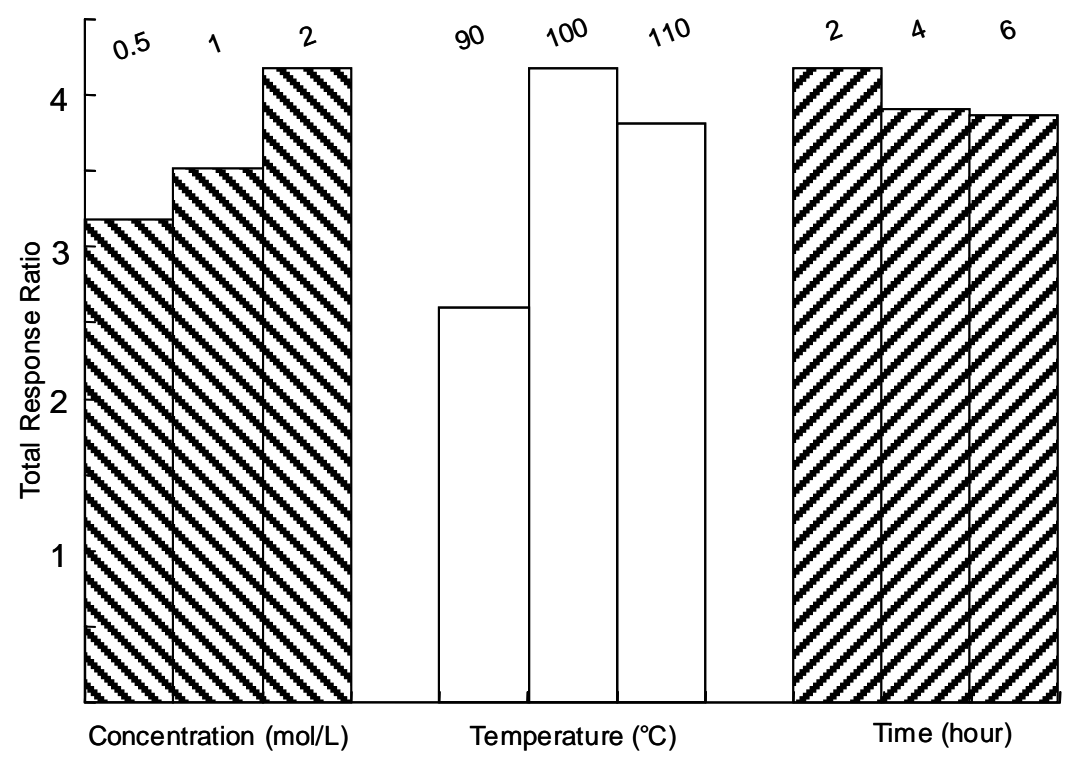




\subsection{Optimization of Pressurized Liquid Extraction (PLE)}

PLE is a rapid and effective method for sample preparation of carbohydrates [30,31]. Though monosaccharides and polysaccharides could be both extracted in one pressurized water extraction, miscalculation of conjugated carbohydrate contents could result because of the degradation of free carbohydrates in the samples during the acid hydrolysis of polysaccharides. Herein, a stepwise aqueous alcohol and water PLE method was applied for sample preparation based on the different polarity and solubility of the analytes in water. The parameters, including solvent, extraction temperature, static time and extraction cycle were optimized for complete extraction (Figure 3). The response ratio (peak area of analyte/peak area of IS) of free carbohydrates and polysaccaride were used for determination, respectively. The results showed that the optimized PLE parameters were: first, the free carbohydrates were extracted completely (no free sugars could be detected in the second - step water extract) by $70 \%$ aqueous ethanol, then the residue was used for the secondary water extract under $100{ }^{\circ} \mathrm{C}$ to obtain polysaccharides; the static time was $10 \mathrm{~min}$ and one static cycle, pressure was set at default value $\left(1.034 \times 10^{4} \mathrm{kPa}\right)$ for both steps.

Figure 3. Optimization of pressurized liquid extraction of carbohydrates in Cordyceps.

$(\Delta)$ ) Free carbohydrates, ( $\square$ ) polysaccarides.

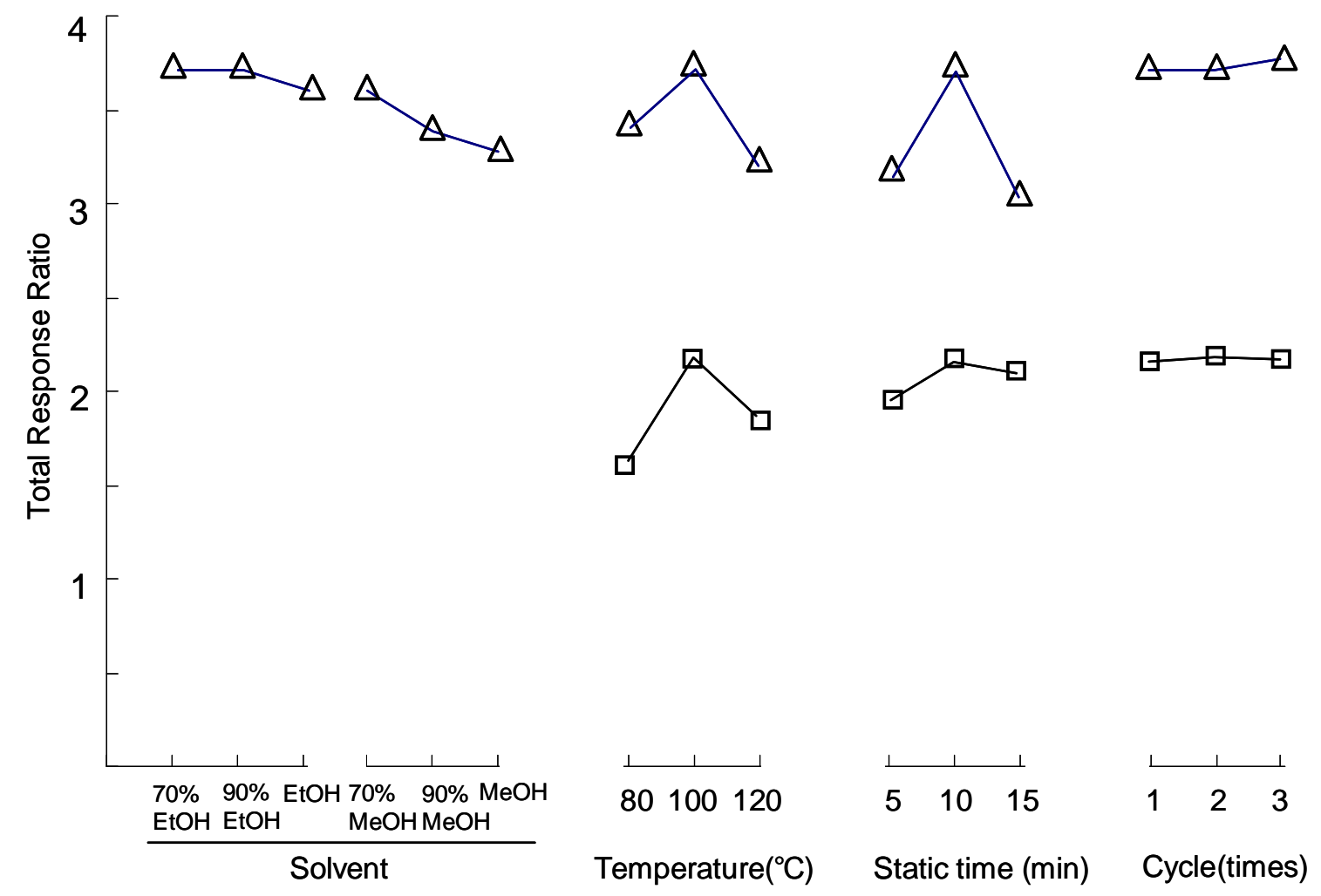

\subsection{Method Validation}

The selected ion monitoring (SIM) method was applied for accurate determination of the saccharides. Characteristic fragment ions, i.e. $\mathrm{m} / \mathrm{z} 129$ for rhamnose, $\mathrm{m} / \mathrm{z} 345$ for fructose and sorbose, $\mathrm{m} / \mathrm{z} 115$ for seven other monosaccharides and IS, were selected for quantification (Table 1). The 
ketoses (fructose and sorbose) produced two peaks which represented their derivatives with syn and anti orientation [27], so the sum of peak area was used for their quantification. A series of amounts of stock solution containing 10 monosaccharides (from $60 \mu \mathrm{g}$ to $2000 \mu \mathrm{g}$ for each monosaccharide) were analyzed to establish calibration curves. The curves were constructed by plotting the response ratio i.e. the amount of each monosaccharide. Good linearities $\left(\mathrm{R}^{2}>0.9820\right)$ were obtained within the test ranges. The limits of quantification (LOQs) and detection (LODs) were $0.16-1.60 \mathrm{ng}$ and 0.08-0.98 ng, respectively (Table 1 ).

Table 1. Calibration data and LOQ, LOD for the derivatives of 10 monosacharides.

\begin{tabular}{|c|c|c|c|c|c|c|}
\hline \multirow{2}{*}{ Analytes } & \multirow{2}{*}{$\begin{array}{l}\text { SIM } \\
(m / z)\end{array}$} & \multicolumn{3}{|c|}{ Linear regression data } & \multirow{2}{*}{$\begin{array}{c}\text { LOQ } \\
\text { (ng) }\end{array}$} & \multirow{2}{*}{$\begin{array}{r}\text { LOD } \\
\text { (ng) }\end{array}$} \\
\hline & & Regression equation & $\mathbf{R}^{2}$ & $\begin{array}{c}\text { Test range } \\
\text { (ng) }\end{array}$ & & \\
\hline Rhamnose & 129 & $y=0.0407 x-0.0026$ & 0.9996 & $0.96-31.94$ & 0.33 & 0.08 \\
\hline Ribose & 115 & $y=0.0476 x+0.0283$ & 0.9908 & $0.97-32.38$ & 0.16 & 0.08 \\
\hline Arabinose & 115 & $y=0.0405 x-0.0025$ & 0.9993 & $0.97-32.28$ & 0.17 & 0.08 \\
\hline Xylose & 115 & $y=0.0421 x-0.0015$ & 0.9995 & $0.96-32.12$ & 0.45 & 0.08 \\
\hline Mannose & 115 & $y=0.0402 x-0.0068$ & 0.9996 & $0.97-32.41$ & 0.16 & 0.08 \\
\hline Glucose & 115 & $y=0.0361 x-0.0046$ & 0.9997 & $0.96-32.04$ & 0.16 & 0.13 \\
\hline Galactose & 115 & $y=0.0361 x-0.0095$ & 0.9993 & $0.98-32.52$ & 0.33 & 0.17 \\
\hline Mannitol & 115 & $y=0.0746 x+0.0038$ & 0.9996 & $1.93-64.28$ & 0.25 & 0.12 \\
\hline Fructose & 345 & $y=0.0512 x-0.1583$ & 0.9820 & $3.26-32.65$ & 1.60 & 0.98 \\
\hline Sorbose & 345 & $y=0.0598 x-0.1297$ & 0.9927 & $1.61-32.18$ & 1.29 & 0.88 \\
\hline
\end{tabular}

The overall intra and inter-day variations of seven aldoses and mannitol were less than 5.19\% (RSD\%), and the accuracy was between $87.38 \%$ and $103.15 \%$. Two ketoses (fructose and sorbose) gave the accuracy from $76.63 \%$ to $101.42 \%$ with RSD\% between $1.56 \%$ and $18.04 \%$ (Table 2).

Table 2. Short and long term accuracy of the analytical method.

\begin{tabular}{|c|c|c|c|c|c|c|c|c|c|}
\hline \multirow{3}{*}{ Analyte } & \multirow{3}{*}{$\begin{array}{c}\text { Contain } \\
\text { (ng) }\end{array}$} & \multicolumn{4}{|c|}{ Short term $(n=6)$} & \multicolumn{4}{|c|}{ Long term $(n=6)$} \\
\hline & & \multirow{2}{*}{$\begin{array}{l}\text { Found } \\
\text { (ng) }\end{array}$} & \multirow{2}{*}{$\begin{array}{l}\text { Accuracy } \\
(\%)^{a}\end{array}$} & \multicolumn{2}{|c|}{ RSD (\%) } & \multirow{2}{*}{$\begin{array}{l}\text { Found } \\
\text { (ng) }\end{array}$} & \multirow{2}{*}{$\begin{array}{l}\text { Accuracy } \\
(\%)\end{array}$} & \multicolumn{2}{|c|}{ RSD (\%) } \\
\hline & & & & $\mathrm{Rt}_{\mathrm{R}}{ }^{\mathrm{b}}$ & $\mathbf{R P a}^{\mathrm{c}}$ & & & $\mathbf{R t}_{\mathrm{R}}$ & $\mathbf{R P a}$ \\
\hline \multirow[t]{3}{*}{ Rhamnose } & 3.19 & 3.11 & 97.45 & 0.01 & 1.22 & 3.11 & 97.56 & 0.07 & 1.55 \\
\hline & 15.97 & 15.65 & 98.17 & 0.02 & 1.40 & 15.55 & 97.58 & 0.06 & 1.38 \\
\hline & 25.55 & 25.12 & 98.52 & 0.05 & 1.04 & 25.25 & 99.01 & 0.09 & 1.21 \\
\hline \multirow[t]{3}{*}{ Ribose } & 3.24 & 2.82 & 87.38 & 0.02 & 0.97 & 3.11 & 88.36 & 0.06 & 1.27 \\
\hline & 16.19 & 16.67 & 103.15 & 0.02 & 0.72 & 16.46 & 103.15 & 0.06 & 5.19 \\
\hline & 25.91 & 24.28 & 93.89 & 0.05 & 1.11 & 24.27 & 93.88 & 0.11 & 1.03 \\
\hline
\end{tabular}


Table 2. Cont.

\begin{tabular}{|c|c|c|c|c|c|c|c|c|c|}
\hline \multirow[t]{3}{*}{ Arabinose } & 3.23 & 3.12 & 96.86 & 0.01 & 0.79 & 3.13 & 97.14 & 0.07 & 1.07 \\
\hline & 16.14 & 15.58 & 96.70 & 0.02 & 0.93 & 15.56 & 96.58 & 0.05 & 1.65 \\
\hline & 25.82 & 25.58 & 99.21 & 0.04 & 0.83 & 25.71 & 99.74 & 0.10 & 0.62 \\
\hline \multirow[t]{3}{*}{ Xylose } & 3.21 & 3.16 & 98.53 & 0.02 & 1.59 & 3.17 & 98.90 & 0.07 & 1.49 \\
\hline & 16.06 & 15.68 & 97.79 & 0.04 & 0.84 & 15.61 & 97.42 & 0.07 & 1.05 \\
\hline & 25.69 & 25.45 & 99.23 & 0.05 & 0.78 & 25.63 & 99.94 & 0.11 & 1.13 \\
\hline \multirow[t]{3}{*}{ Mannose } & 3.24 & 3.13 & 96.86 & 0.01 & 1.42 & 3.17 & 97.92 & 0.06 & 1.52 \\
\hline & 16.20 & 15.89 & 98.26 & 0.01 & 0.61 & 15.83 & 97.85 & 0.06 & 0.94 \\
\hline & 25.93 & 25.58 & 98.84 & 0.03 & 0.95 & 25.63 & 99.04 & 0.07 & 0.47 \\
\hline \multirow[t]{3}{*}{ Glucose } & 3.20 & 3.05 & 95.26 & 0.01 & 0.87 & 3.07 & 96.10 & 0.06 & 1.89 \\
\hline & 16.02 & 15.77 & 98.64 & 0.03 & 0.80 & 15.70 & 98.18 & 0.05 & 1.91 \\
\hline & 25.63 & 25.40 & 99.26 & 0.03 & 0.74 & 25.38 & 99.19 & 0.08 & 0.34 \\
\hline \multirow[t]{3}{*}{ Galactose } & 3.25 & 3.06 & 94.38 & 0.01 & 1.13 & 3.08 & 95.01 & 0.06 & 1.46 \\
\hline & 16.26 & 15.71 & 96.80 & 0.03 & 1.89 & 15.84 & 97.56 & 0.06 & 1.69 \\
\hline & 26.02 & 25.85 & 99.54 & 0.03 & 1.05 & 25.93 & 99.84 & 0.08 & 0.06 \\
\hline \multirow[t]{3}{*}{ Mannitol } & 6.43 & 6.20 & 96.64 & 0.01 & 1.24 & 6.20 & 96.69 & 0.03 & 1.39 \\
\hline & 32.14 & 31.60 & 98.49 & 0.02 & 0.33 & 31.53 & 98.26 & 0.04 & 0.95 \\
\hline & 51.42 & 51.14 & 99.62 & 0.02 & 0.58 & 51.15 & 99.64 & 0.06 & 0.41 \\
\hline \multirow[t]{3}{*}{ Fructose } & 3.26 & 2.504 & 76.81 & 0.01 & 4.64 & 2.50 & 76.63 & 0.04 & 18.04 \\
\hline & 16.33 & 16.39 & 100.56 & 0.01 & 2.39 & 14.85 & 91.12 & 0.03 & 8.76 \\
\hline & 26.12 & 25.17 & 96.53 & 0.01 & 7.55 & 24.07 & 92.32 & 0.02 & 5.01 \\
\hline \multirow[t]{3}{*}{ Sorbose } & 3.22 & 2.49 & 77.53 & 0.01 & 4.62 & 2.52 & 78.37 & 0.04 & 12.71 \\
\hline & 16.09 & 16.29 & 101.42 & 0.01 & 1.56 & 15.51 & 96.57 & 0.03 & 4.91 \\
\hline & 25.74 & 24.73 & 96.25 & 0.01 & 5.43 & 23.98 & 93.33 & 0.02 & 4.65 \\
\hline
\end{tabular}

${ }^{\mathrm{a}}$ Accuracy $(\%)=100 \times$ mean of measured concentration/nominal concentration; ${ }^{\mathrm{b}} \mathrm{Rt}_{\mathrm{R}}$, relative retention time of analytes to internal standard (IS); ${ }^{\mathrm{C}} \mathrm{RPa}$, relative peak area ratio of analytes to IS.

Moreover, known amount of 10 monosaccharides were added into an accurately weighted sample (natural Cordyceps sinensis from Zhongqiao) for calculating recoveries. The mixture was extracted and analyzed using the method mentioned above. The overall recovery was range from $83.8 \%$ 104.5\% for the analytes (Table 3). The results indicated the method is simple, sensitive and feasible for determination of investigated carbohydrates.

Table 3. Recoveries of 10 monosacharides for the analytical method.

\begin{tabular}{lccccc}
\hline Analyte & Original (ng) & Spiked (ng) & Found $^{\mathbf{a}}(\mathbf{n g})$ & Recovery $^{\mathbf{b}} \mathbf{( \% )}$ & RSD (\%) $^{\text {\% }}$ \\
\hline Rhamnose & $-{ }^{\mathrm{c}}$ & 3.83 & 3.54 & 92.3 & 4.7 \\
Ribose & - & 3.89 & 3.61 & 93.0 & 3.9 \\
Arabinose & - & 3.87 & 3.67 & 94.7 & 5.6 \\
Xylose & - & 3.85 & 3.68 & 95.4 & 3.2 \\
Mannose & - & 3.89 & 4.06 & 104.5 & 3.4 \\
Glucose & 1.78 & 3.84 & 5.72 & 102.4 & 4.6 \\
\hline
\end{tabular}


Table 3. Cont.

\begin{tabular}{lccccc}
\hline Galactose & - & 3.90 & 3.76 & 96.3 & 6.1 \\
Mannitol & 34.85 & 7.71 & 41.97 & 92.2 & 4.6 \\
Fructose & - & 3.92 & 3.28 & 83.8 & 7.0 \\
Sorbose & - & 3.86 & 3.43 & 88.9 & 9.3 \\
\hline
\end{tabular}

${ }^{\mathrm{a}}$ The data was present as average of three determinations; ${ }^{\mathrm{b}}$ Recovery $(\%)=100 \times$ (amount foundoriginal amount)/amount spiked; ${ }^{\mathrm{c}}$ Undetectable.

\subsection{Compositional Sugars in Polysaccharides}

Next the molar ratio value of released monosacchrides in the polysaccharides was determined after hydrolysis using known amounts of authentic monosaccharide standards as reference. The results are shown in Table 4. Polysaccharides in natural C. sinensis (NCS) were usually composed of mannose, glucose and galactose with a molar ratio of 1.00:16.61 3.82:1.60 1.28. Otherwise, the compositional saccharides and their molar ratios of cultured $C$. sinensis (CCS) and cultured C. militaris (CCM) were 1.00:3.01 1.09:3.30 1.05 (except the Hongkong sample) and 1.00:2.86 1.28:1.07 0.78, respectively, besides, some samples contained traces of ribose, arabinose and xylose. Generally, more types of saccharides were found in polysaccharides of cultured Cordyceps than in those of natural Cordyceps (Figure 4).

Table 4. Molar ratio of compositional sugars of polysaccharides in natural and cultured Cordyceps.

\begin{tabular}{|c|c|c|c|c|c|c|}
\hline Samples & Ribose & Arabinose & Xylose & Mannose & Glucose & Galactose \\
\hline \multicolumn{7}{|c|}{ Natural C. sinensis } \\
\hline Zhongqiao & & & & 1.00 & 16.61 & 1.28 \\
\hline Sichuan & & & & 1.00 & 3.82 & 1.40 \\
\hline Qinghai & & & & 1.00 & 4.33 & 1.31 \\
\hline Tibet & & & & 1.00 & 13.65 & 1.60 \\
\hline \multicolumn{7}{|c|}{ Cultured C. sinensis } \\
\hline Wanfeng & & 0.11 & 0.13 & 1.00 & 1.97 & 1.36 \\
\hline Anhui & 0.02 & 0.14 & 0.07 & 1.00 & 1.09 & 1.11 \\
\hline Hebei & 0.24 & & 0.11 & 1.00 & 2.60 & 3.03 \\
\hline HongKong & & & & 1.00 & 25.40 & 0.46 \\
\hline Huadong & 0.05 & & & 1.00 & 3.01 & 1.05 \\
\hline Jiangxi & & 0.32 & 0.15 & 1.00 & 1.18 & 1.96 \\
\hline \multicolumn{7}{|c|}{ Cultured C. militaris } \\
\hline Aoli & & & & 1.00 & 2.86 & 0.78 \\
\hline Xiankang & 0.01 & & & 1.00 & 2.17 & 0.93 \\
\hline Quanxin & 0.14 & & & 1.00 & 1.28 & 1.07 \\
\hline
\end{tabular}


Figure 4. Typical SIM chromatograms of mixed standards (A), free (left) and conjunct carbohydrates (right) in natural Cordyceps sinensis (B), cultured C. sinensis (C), cultured C. militaris (D). Rha, rhamnose; Rib, ribose; Ara, arabinose; Xyl, xylose; Man, mannose; Glu, glucose; Gal, galactose; Ma-ol, mannitol; Fru, fructose; Sor, sorbose; IS, internal standard.
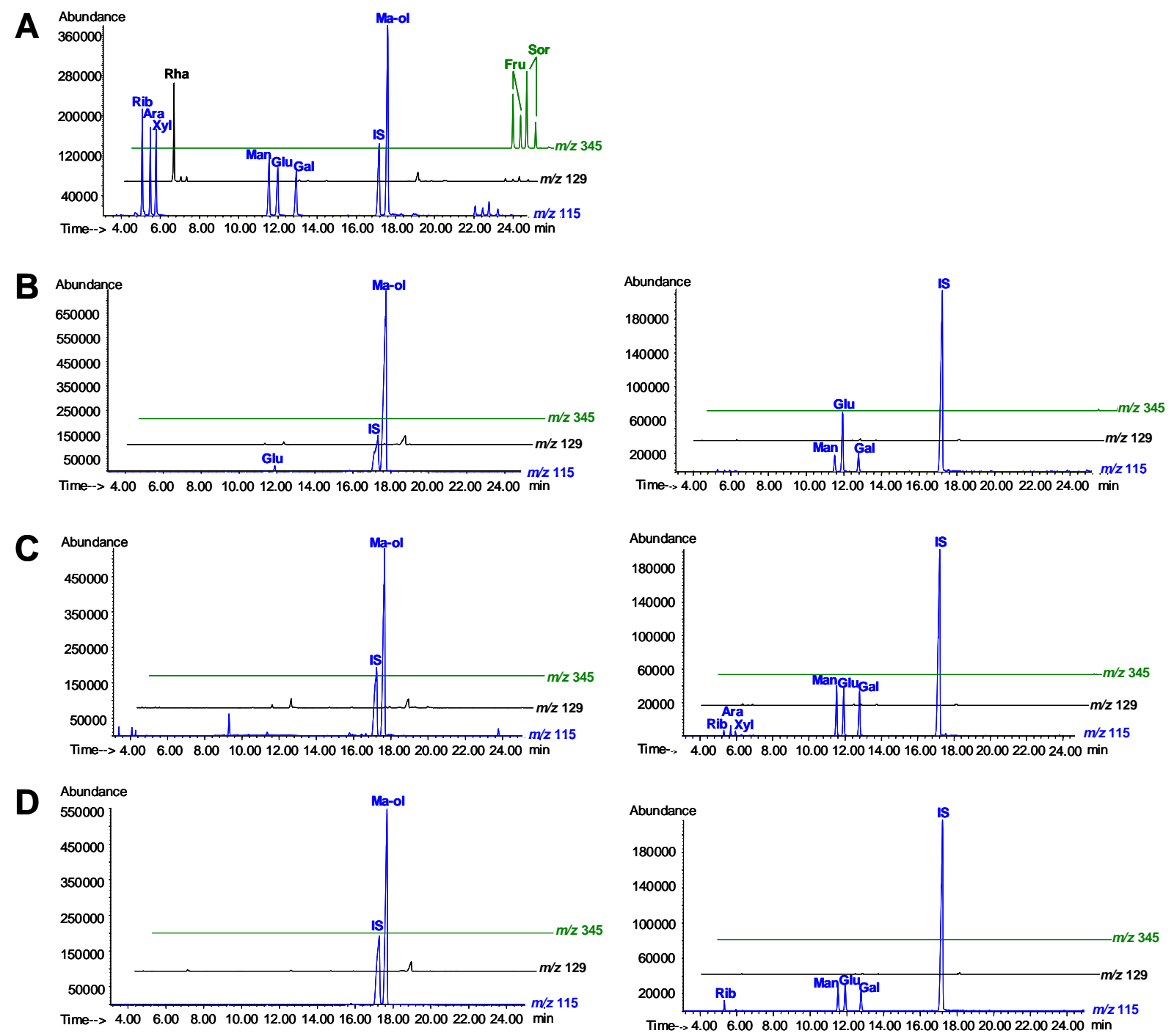

\subsection{Quantitation of Free Carbohydrates}

The contents of free carbohydrates were the values of measuring $70 \%$ ethanol extracts after direct derivatization. Data were summarized in Table 5. NCS contained the highest amounts of mannitol ( $\geq 7.99 \%$ ) and a little amount of glucose. However, mannitol in both cultured CCS and cultured CCM were less than 5.83\%, and free glucose was only detected in few samples (CCS from HongKong, CCM from Aoli and Xiankang). The displayed distinction between natural and cultured Cordyceps is according with previous reports [8]. 
Table 5. Contents of free and conjunct carbohydrates (mg per $100 \mathrm{mg}$ ) in natural and cultured Cordyceps.

\begin{tabular}{|c|c|c|c|c|c|c|c|c|c|c|c|c|c|c|}
\hline \multirow{2}{*}{ Analyte } & & \multicolumn{4}{|c|}{ Natural C. sinensis } & \multicolumn{6}{|c|}{ Cultured C. sinensis } & \multicolumn{3}{|c|}{ Cultured C. militaris } \\
\hline & & Zhongqiao & Sichuan & Qinghai & Tibet & Wanfeng & Anhui & Hebei & HongKong & Huadong & Jiangxi & Aoli & Xiankang & Quanxin \\
\hline \multirow[t]{2}{*}{ Rhamnose } & $\mathrm{F}^{\mathrm{a}}$ & $-b$ & - & - & - & - & - & - & - & - & - & - & - & - \\
\hline & $\mathrm{C}$ & - & - & - & - & - & - & - & - & - & - & - & - & - \\
\hline \multirow[t]{2}{*}{ Ribose } & $\mathrm{F}$ & - & - & - & - & - & - & - & - & - & - & - & - & - \\
\hline & $\mathrm{C}$ & - & - & - & - & - & \pm & 0.02 & - & \pm & - & - & \pm & \pm \\
\hline \multirow[t]{2}{*}{ Arabinose } & $\mathrm{F}$ & - & - & - & - & - & - & - & - & - & - & - & - & - \\
\hline & $\mathrm{C}$ & - & - & - & - & \pm & \pm & - & - & - & 0.23 & - & - & - \\
\hline \multirow[t]{2}{*}{ Xylose } & $\mathrm{F}$ & - & - & - & - & - & - & - & - & - & - & - & - & - \\
\hline & $\mathrm{C}$ & - & - & - & - & \pm & \pm & \pm & - & - & \pm & - & - & - \\
\hline \multirow[t]{2}{*}{ Mannose } & $\mathrm{F}$ & - & - & - & - & - & - & - & - & - & - & - & - & - \\
\hline & $\mathrm{C}$ & $0.15^{\mathrm{c}}$ & 0.19 & 0.24 & 0.25 & 0.60 & 0.72 & 0.42 & 0.20 & 0.46 & 0.89 & 0.24 & 0.28 & 0.32 \\
\hline \multirow[t]{2}{*}{ Glucose } & $\mathrm{F}$ & 0.29 & $\pm^{\mathrm{d}}$ & \pm & 0.13 & - & - & - & \pm & - & - & \pm & 0.13 & - \\
\hline & $\mathrm{C}$ & 2.51 & 0.73 & 1.03 & 3.37 & 1.17 & 0.79 & 1.09 & 5.03 & 1.39 & 1.05 & 0.70 & 0.60 & 0.41 \\
\hline \multirow[t]{2}{*}{ Galactose } & $\mathrm{F}$ & - & - & - & - & - & - & - & - & - & - & - & - & - \\
\hline & $\mathrm{C}$ & 0.19 & 0.27 & 0.31 & 0.39 & 0.81 & 0.80 & 1.27 & \pm & 0.48 & 1.74 & 0.19 & 0.26 & 0.34 \\
\hline Mannitol & $\mathrm{F}$ & 8.14 & 9.76 & 7.99 & 10.74 & 5.83 & 4.01 & 4.44 & 0.94 & 2.24 & 4.30 & 3.16 & 4.09 & 3.96 \\
\hline \multirow[t]{2}{*}{ Fructose } & $\mathrm{F}$ & - & - & - & - & - & - & - & - & - & - & - & - & - \\
\hline & $\mathrm{C}$ & - & - & - & - & - & - & - & - & - & - & - & - & - \\
\hline \multirow[t]{2}{*}{ Sorbose } & $\mathrm{F}$ & - & - & - & - & - & - & - & - & - & - & - & - & - \\
\hline & $\mathrm{C}$ & - & - & - & - & - & - & - & - & - & - & - & - & - \\
\hline
\end{tabular}

${ }^{\mathrm{a}}$ F, free carbohydrates; C, polysaccarides; ${ }^{\mathrm{b}}$ Undetectable; ${ }^{\mathrm{c}}$ Average of duplicates; ${ }^{\mathrm{d}}$ Under the limits of quantitation. 


\subsection{Quantitation of Conjunct Carbohydrates}

The contents of conjunct carbohydrates were the values obtained by measuring water extracts after TFA hydrolysis and derivatization. After hydrolysis, the contents of glucose increased significantly in all of samples, and galactose and mannose could also be calculated (Table 5). The glucose released from polysaccharides in $C$. sinensis (0.73 5.03\%) was higher than that in C. militaris $(0.41-0.70 \%)$, while galactose and mannose found in polysaccharides from NCS, CCS and CCM were 0.19-0.39\% and $0.15-0.25 \%, 0.48-1.74 \%$ and $0.42-0.89 \%$, as well as $0.19-0.34 \%$ and $0.24-0.32 \%$, respectively. Besides, trace ribose, arabinose and xylose could be mainly found in CCS, while only trace ribose contained in CCM. More types of saccharides contained in CCS might derive from the culture media, which need further investigation.

Figure 5. Dendrograms of hierarchical cluster analysis resulting from the content of free (A) and conjunct (B) carbohydrates in 13 samples of Cordyceps.
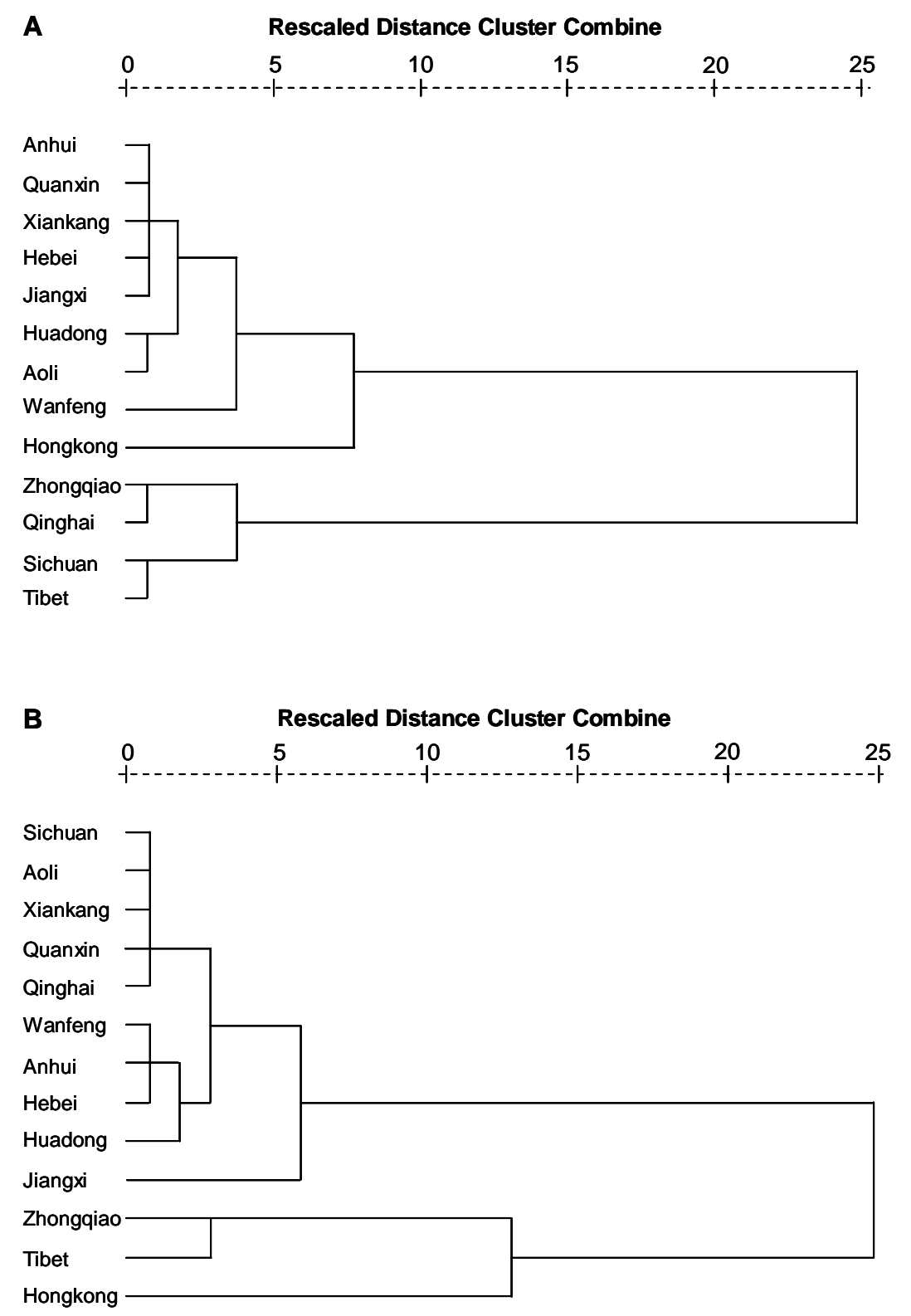


\subsection{Comparison of natural and cultured Cordyceps}

Hierarchical cluster analysis was preformed depend on the content of free saccharides and conjunct carbohydrates (Figure 5). The results showed natural and cultured Cordyceps could be grouped into two clusters, which indicated the carbohydrates are helpful for the characterization. However, there were no clear clusters to discriminate NCS, CCS and CCM, perhaps because the total contents had no significant differences, even though the types of carbohydrates contained in the polysaccharides varied

\section{Experimental Section}

\subsection{Materials and Chemicals}

Natural C. sinensis were obtained from Sichuan, Tibet, Qinghai provinces and Zhongqiao Herbal Store in Macau (originally from Tibet); Cultured $C$. sinensis were obtained from Wanfeng (Wanfeng Medicines Group Co. Ltd., Zhejiang Province), Anhui (Anhui Agricultural University, Anhui Province), Hebei (Boding Pharmaceutical Factory, Hebei Province), Hongkong (The Hong Kong University of Science and Technology, Hongkong), Huadong (Huadong Medicines Group Co. Ltd., Zhejiang Province) and Jiangxi (Chinese Medicine Factory of Jiangxi, Jiangxi Province); Cultured $C$. militaris, one of the substitutes of $C$. sinensis, were obtained from Aoli (Zhangjiagang Aoli Bio-health Products Co. Ltd., Jiangsu Province), Xiankang (Zhuhai Xiankang Bio-Tech Co. Ltd., Guangdong Province) and Quanxin (Quanxin Company, Malaysia). The botanical origin of materials was identified by corresponding author and the voucher specimens were deposited at the Institute of Chinese Medical Sciences, University of Macau, Macau, China. L-Rhamnose, D-ribose, D-arabinose, D-xylose, Dmannose, D-glucose, D-galactose, D-mannitol, D-fructose and L-sorbose were purchased from Sigma (St. Louis, MO, USA). A stock solution containing mannitol $\left(\sim 2 \mathrm{mg} \cdot \mathrm{mL}^{-1}\right)$ and other nine monosaccharides ( $\sim \mathrm{mg} \cdot \mathrm{mL}^{-1}$ for each) was prepared in pyridine (ReagentPlus, $\geq 99 \%$, Sigma-Aldrich). A solution containing hydroxylamine hydrochloride (analytically pure, $\sim 20 \mathrm{mg} \cdot \mathrm{mL}^{-1}$ ) was prepared in pyridine for derivatization of saccharides. About $100 \mathrm{mg}$ myo-inositol hexaacetate (prepared according to the reference [29], $>99 \%$ as determined by GC-MS) was dissolved in chloroform ( $25 \mathrm{~mL})$ as an IS solution. These solutions were all stored at $4{ }^{\circ} \mathrm{C}$. Trifluoroacetic acid (TFA, 99\%) was purchased from Riedel-de Haën (Seelze, Germany). Acetic anhydride and chloroform were analytical grade reagents. Water was obtained from a Millipore water-purification system (Millipore, Bedford, MA, USA).

\subsection{Pressurized Liquid Extraction}

PLE was performed on a Dionex ASE 200 system (Dionex Corp., Sunnyvale, CA, USA) in two steps under optimized conditions. Dried powder of Cordyceps ( $\sim .1 \mathrm{~g}$ ) was mixed with diatomaceous earth in a proportion 1:1 and placed into an $11 \mathrm{~mL}$ stainless steel extraction cell, then extracted with $70 \%$ aqueous ethanol under $100{ }^{\circ} \mathrm{C}$ for $10 \mathrm{~min}$ of static time for 1 cycle with pressure at $1.034 \times 10^{4} \mathrm{kPa}$. The extract purged out by nitrogen was transferred into a $25 \mathrm{~mL}$ volumetric flask, which was made up to its volume with the bsame solvent for the analysis of free carbohydrates. The residue was further extracted with water under $100{ }^{\circ} \mathrm{C}$ for $10 \mathrm{~min}$ of static time for 1 cycle with 
pressure at $1.034 \times 10^{4} \mathrm{kPa}$. The extract was also transferred into a $25 \mathrm{~mL}$ volumetric flask which was made up to its volume with water for the analysis of conjunct carbohydrates.

\subsection{TFA Hydrolysis}

An aliquot $(10 \mathrm{~mL})$ of PLE water extract was evaporated to dryness, then hydrolyzed with $2 \mathrm{~mol} \cdot \mathrm{L}^{-1}$ TFA $(1 \mathrm{~mL})$ in a sealed glass tube with screw cap which filled with pure nitrogen gas at $100{ }^{\circ} \mathrm{C}$ for $2 \mathrm{~h}$. The hydrolyzed solution was evaporated to dryness under $45{ }^{\circ} \mathrm{C}$ and then methanol $(1 \mathrm{~mL})$ was added for further evaporation and complete removal of TFA. The hydrolysate was used for derivatization.

\subsection{Derivatization}

For standard monosaccharides, stock solution (1 $\mathrm{mL})$ was treated with hydroxylamine hydrochloride-pyridine solution $(1 \mathrm{~mL})$ in a sealed glass tube with a screw cap at $90{ }^{\circ} \mathrm{C}$ for $30 \mathrm{~min}$. After cooling to room temperature, acetic anhydride $(1 \mathrm{~mL})$ was added and heating continued for another $30 \mathrm{~min}$ in the resealed tube. The cooled solution was evaporated to dryness under diminished pressure at $45{ }^{\circ} \mathrm{C}$. The residue was dissolved in dry chloroform $(2 \mathrm{~mL})$ and IS solution $(500 \mu \mathrm{L})$ was added. The mixture was filtered through $0.45 \mu \mathrm{m}$ syringe filter (Agilent Technologies) prior to injection into GC-MS system. For free carbohydrates and polysacarides, an aliquot $(10 \mathrm{~mL})$ of the extracts was evaporated to dryness. The residue was reacted with hydroxylamine hydrochloride and acetic anhydride to form the derivatives directly as in the procedures mentioned above for free carbohydrate determination. The dried residue of acidic hydrolyzed polysaccharides was derivatized for polysaccaride determination.

\subsection{GC-MS Analysis}

GC-MS was performed on an Agilent 6890 gas chromatography instrument coupled with an Agilent 5973 mass spectrometer (Agilent Technologies, Palo Alto, CA, USA). A HP-5MS capillary column (30 $\mathrm{m} \times 0.25 \mathrm{~mm}$, i.d.) coated with $0.25 \mu \mathrm{m}$ film $5 \%$ phenyl methyl siloxane was used for separation. The column temperature was set at $175{ }^{\circ} \mathrm{C}$ and held for $7 \mathrm{~min}$, then programmed at $5{ }^{\circ} \mathrm{C} \cdot \mathrm{min}^{-1}$ to $185^{\circ} \mathrm{C}$ and held for $5 \mathrm{~min}$, then at $4{ }^{\circ} \mathrm{C} \cdot \mathrm{min}^{-1}$ to $230^{\circ} \mathrm{C}$. Split injection $(2 \mu \mathrm{L})$ with a split ratio of 1:50 was applied. High purity helium was used as carrier gas with flow rate of $1.0 \mathrm{~mL} \cdot \mathrm{min}^{-1}$. The mass spectrometer was operated in electron-impact (EI) mode, the scan range was 40-550 amu, the ionization energy was $70 \mathrm{eV}$ and the scan rate was $2.89 \mathrm{~s}$ per scan. The inlet, ionization source temperature were 250 and $280{ }^{\circ} \mathrm{C}$, respectively.

\subsection{Data Analysis}

Hierarchical cluster analysis was performed by SPSS 13.0 for Windows (SPSS Inc., Chicago, IL, USA), which comprise a number of "procedures” - graphical, statistical, reporting, processing and tabulating procedures - that enable simple and rapid data evaluation. Average Linkage between groups was selected as measurement for hierarchical clustering analysis. 


\section{Conclusions}

Free carbohydrates and polysaccharides in natural and cultured Cordyceps were qualitatively and quantitatively determined using a stepwise pressurized liquid extraction and gas chromatography coupled with mass spectrometry. Natural and cultured Cordyceps could also be discriminated by hierarchical clustering analysis based on the contents of free carbohydrates. It is indicated the carbohydrates could be characteristic for evaluation of Cordyceps, and the established method is helpful for elucidating the distinct carbohydrates in samples of different origin.

\section{Acknowledgements}

The research was supported by grants from the Science and Technology Development Found of Macau (028/2006/A2) and University of Macau (UL015A/09-Y2) to S.P. Li.

\section{References}

1. Cummings, J.H.; Stephen, A.M. Carbohydrate terminology and classification. Eur. J. Clin. Nutr. 2007, 61, S5-S18.

2. Wheeler, M.L.; Pi-Sunyer, F.X. Carbohydrate Issues: Type and Amount. J. Am. Diet. Assoc. 2008, 108, S34-S39.

3. Kilcoyne, M.; Joshi, L. Carbohydrates in therapeutics. Cardiovasc. Hematol. Agents Med. Chem. 2007, 5, 186-197.

4. Zhang, M.; Cui, S.W.; Cheung, P.C.K.; Wang, Q. Antitumor polysaccharides from mushrooms a review on their isolation, structural characteristics and antitumor activity. Trends Food Sci. Tech. 2007, 18, 4-19.

5. Schepetkin, I.A.; Quinn, M.T. Botanical polysaccharides Macrophage immunomodulation and therapeutic potential. Int. Immunopharmacol. 2006, 6, 317-333.

6. Zhu, J.S.; Halpern, G.M.; Johns, K. The scientific rediscovery of an ancient Chinese herbal medicine: Cordyceps sinensis: Part I. J. Alt. Comp. Med. 1998, 4, 289-303.

7. Zhu, J.S.; Halpern, G.M.; Johns, K. The scientific rediscovery of an ancient Chinese herbal medicine: Cordyceps sinensis: Part II. J. Alt. Comp. Med. 1998, 4, 429-457.

8. Li, S.P.; Yang, F.Q.; Tsim, K.W.K. Quality control of Cordyceps sinensis, a valued traditional Chinese medicine. J. Pharm. Biomed. Anal. 2006, 41, 1571-1584.

9. Ng, T.B.; Wang, H.X. Pharmacological actions of Cordyceps, a prized folk. J. Pharm. Pharmacol. 2005, 57, 1509-1519.

10. Paterson, R.R.M. Cordyceps - A traditional Chinese medicine and another fungal therapeutic biofactory? Phytochemistry 2008, 69, 1469-1495.

11. Kiho, T.; Ookubo, K.; Usui, S.; Ukai, S.; Hirano, K. Strcture features and hypoglycemic activity of a polysaccharide (CF-F10) from the cultured mycelium of Cordyceps sinensis. Biol. Pharm. Bull. 1999, 22, 966-970. 
12. Kiho, T.; Ji, H.; Yamane, A.; Ukai, S. Polysaccharides in fungi. XXXII. Hypoglycemic activity and chemical properties of a polysaccharide from the cultural mycelium of Cordyceps sinensis. Biol. Pharm. Bull. 1993, 16, 1291-1293.

13. Li, S.P.; Zhao, K.J.; Ji, Z.N.; Song, Z.H.; Dong, T.T.X.; Lo, C.K.; Cheung, J.K.H.; Zhu, S.Q.; Tsim, K.W.K. A polysaccharide isolated from Cordyceps sinensis, a traditional Chinese medicine, protects PC12 cells against hydrogen peroxide-induced injury. Life Sci. 2003, 73, 2503-2513.

14. Li, S.P.; Zhang, G.H.; Zeng, Q.; Huang, Z.G.; Wang, Y.T.; Dong, T.T.X.; Tsim, K.W.K. Hypoglycemic activity of polysaccharide, with antioxidation, isolated from cultured Cordyceps mycelia. Phytomedicine 2006, 13, 428-433.

15. Yu, R.M.; Song, L.Y.; Zhao, Y.; Bin, W.; Wang, L.; Zhang, H.; Wu, Y.H.; Ye, W.C.; Yao, X.S. Isolation and biological properties of polysaccharide CPS-1 from cultured Cordyceps militaris. Fitoterapia 2004, 75, 465-472.

16. Chang, H.L.; Chao, G.R.; Chen, C.C.; Mau, J.L. Non-volatile components of Agaricus blazei, Antrodia camphorate and Cordyceps militaris mycelia. Food Chem. 2001, 74, 203-207.

17. Huang, S.J.; Tsai, S.Y.; Lee, Y.L.; Mau, J.L. Nonvolatile taste components of fruit bodies and mycelia of Cordyceps militaris. LWT-Food Sci. Tech. 2006, 39, 577-583.

18. Liu, G.P. Advance on the methods for determination of polysaccharides from Cordyceps. Yao Xue Shi Jian Za Zhi 2008, 26, 53-68.

19. Fox, A. Carbohydrate profiling of bacteria by gas chromatography-mass spectrometry and their trace detection in complex matrices by gas chromatography-tandem mass spectrometry. $J$. Chromatogr. A 1999, 843, 287-300.

20. Kim, J.S.; Laskowich, E.R.; Arumugham, R.G.; Kaiser, R.E.; MacMichael, G.J. Determination of saccharide content in pneumococcal polysaccharides and conjugate vaccines by GC-MSD. Anal. Biochem. 2005, 347, 262-274.

21. Medeiros, P.M.; Simoneit, B.R.T. Analysis of sugars in environmental samples by gas chromatography-mass spectrometry. J. Chromatogr. A 2007, 1141, 271-278.

22. Wang, Q.J.; Fang, Y.Z. Analysis of sugars in traditional Chinese drugs. J. Chromatogr. B 2004 812, 309-324.

23. Zhang, W.; He, H.; Zhang, X. Determination of neutral sugars in soil by capillary gas chromatography after derivatization to aldononitrile acetates. Soil Biol. Biochem. 2007, 39, 2665-2669.

24. Guerrant, G.O.; Moss, C.W. Determination of monosaccharides as aldononitrile, O-methyloxime, alditol, and cyclitol acetate derivatives by gas chromatography. Anal. Chem. 1984, 56, 636-638.

25. Varma, R.; Varma, R.S.; Wardi, A.H. Separation of aldononitrile acetates of neutral sugars by gasliquid chromatography and its applications to polysaccharides. J. Chromatogr. 1973, 77, 222-227.

26. Seymour, F.R.; Chen, E.C.M.; Bishop, S.H. Identification of aldoses by use of their peracetylated aldononitrile derivatives: A G.L.C.-M.S. approach. Carbohydr. Res. 1979, 73, 19-45. 
27. Seymour, F.R.; Chen, E.C.M.; Stouffer, J.E. Identification of ketoses by use of their peracetylated oxime derivatives: A G.L.C.-M.S. approach. Carbohydr. Res. 1980, 83, 201-242.

28. Seymour, F.R.; Unruh, S.L.; Nehlich, D.A. Quantitation of free sugars in plant tissue by G.L.C. of their peracetylated aldononitrile and ketoxime derivatives. Carbohydr. Res. 1989, 191, 175-189.

29. Li, T.L.; Wu, C.X.; Zhang, Y.X. Studies of gas chromatographic analysis of saccharides and alditols II. Some improvements in the analysis of acetylated aldononitriles by gas chromatography. Chin. J. Anal. Chem. 1981, 10, 272-276.

30. Sanz, M.L.; Martínez-Castro, I. Recent developments in sample preparation for chromatographic analysis of carbohydrates. J. Chromatogr. A 2007, 1153, 74-89.

31. Ruiz-Matute, A.I.; Ramos, L.; Martínez-Castro, I.; Sanz, M.L. Fractionation of honey carbohydrates using pressurized liquid extraction with activated charcoal. J. Agric. Food Chem. 2008, 56, 8309-8313.

Sample Availability: Samples of the compounds and materials are available from the authors.

(C) 2010 by the authors; licensee MDPI, Basel, Switzerland. This article is an Open Access article distributed under the terms and conditions of the Creative Commons Attribution license (http://creativecommons.org/licenses/by/3.0/). 